\title{
dePression, ANxiety, and acaDEMImiC performance in COVID- 19: The PANDEMIC study: A cross-sectional survey study
}

\section{Francisco José Barbosa-Camacho}

Unidad de Investigación Biomédica 02 Hospital de Especialidades, Instituto Mexicano del Seguro Social Olaya Moramay Romero-Limón

Hospital Civil de Guadalajara "Fray Antonio Alcalde", Universidad de Guadalajara

\section{Juan Carlos Ibarrola-Peña}

Unidad de Investigación Biomédica 02 Hospital de Especialidades, Instituto Mexicano del Seguro Social

\section{Yolanda Lorelei Almanza-Mena}

Unidad de Investigación Biomédica 02 Hospital de Especialidades, Instituto Mexicano del Seguro Social

Kevin Josue Pintor-Belmontes

Unidad de Investigación Biomédica 02 Hospital de Especialidades, Instituto Mexicano del Seguro Social

\section{Veronica Alexandra Sánchez-López}

Unidad de Investigación Biomédica 02 Hospital de Especialidades, Instituto Mexicano del Seguro Social

\section{Jonathan Matias Chejfec-Ciociano}

Unidad de Investigación Biomédica 02 Hospital de Especialidades, Instituto Mexicano del Seguro Social

\section{Bertha Georgina Guzmán-Ramírez}

Unidad de Investigación Biomédica 02 Hospital de Especialidades, Instituto Mexicano del Seguro Social

\section{Clotilde Fuentes-Orozco}

Unidad de Investigación Biomédica 02 Hospital de Especialidades, Instituto Mexicano del Seguro Social

\section{Ana Olivia Cortés-Flores}

Hospital San Javier, Unidad de Cuidados Intensivos

\section{Roberto Carlos Miranda-Ackerman}

Hospital San Javier, Unidad de Cuidados Intensivos

\section{Guillermo Alonso Cervantes-Cardona}

Departamento de Disciplinas Filosófico, Metodológicas e instrumentales, Centro Universitario de Ciencias de la Salud, Universidad de Guadalajara, Guadalajara

\section{Gabino Cervantes-Guevara}

Departamento de Bienestar y Desarrollo Sustentable, Centro Universitario del Norte, Universidad de Guadalajara, Colotlán, Jalisco

\section{Alejandro González-0jeda ( $\sim$ avygail5@gmail.com )}

Unidad de Investigación Biomédica 02 Hospital de Especialidades, Instituto Mexicano del Seguro Social

\section{Research Article}


Keywords: COVID-19, depression, educational needs assessment, educational measurements, anxiety

Posted Date: April 9th, 2021

DOI: https://doi.org/10.21203/rs.3.rs-353928/v1

License: (c) (1) This work is licensed under a Creative Commons Attribution 4.0 International License. Read Full License 


\section{Abstract}

\section{Background}

After almost nine months of social isolation, the high incidence of depression and anxiety is understandable. However, depression and anxiety can adversely affect the quality of life. One of the biggest challenges in this global pandemic is providing education within public and private academic institutes.

\section{Methods}

This study was a cross-sectional survey distributed online from April to June 2020. We used the Patient Health Questionnaire-9 depression screening scale and the General Anxiety Disorder-7 screening scale to identify the presence of mental health disorders such as depression or anxiety in undergraduate and graduate students. We used the Academic Self-Concept Scale to determine whether these disorders altered students' perception of their academic performance.

\section{Results}

A total of 610 students answered the survey: 386 female (63.3\%) and 224 male (36.7\%). Most students (71.5\%) had not participated in online courses before. When asked about their class preferences, 581 students (95.2\%) preferred to be taught in classes. The average Academic Self-Concept Scale score was $2.76 \pm 0.35$. The Academic Self-Concept Scale scores were divided into Confidence and Effort categories, and their respective mean scores were $2.71 \pm 0.37$ and $2.82 \pm 0.45$. The total mean Patient Health Questionnarie- 9 scores were $11.94 \pm 6.90$, and the mean General Anxiety Disorder-7 score was $10.30 \pm 5.66$. There were significant effects of the severity of depression and anxiety on the Academic Self-Concept Scale scores $(p<0.001$ and $p<0.05$, respectively).

\section{Conclusions}

The findings suggest that changing from classroom-based teaching to online delivery is not a challenge for students in the normal situation. However, being quarantined can be stressful and frustrating, which may challenge effective learning.

\section{Trial registration}

The study protocol was submitted to ClinicalTrials.gov and registered with the identifier: NCT04420416.

\section{Background}

"I never teach my pupils; I only attempt to provide the conditions in which they can learn." - Albert Einstein.

In December 2019, the World Health Organization recognized a new viral pneumonia that spread rapidly across the world and caused an outbreak that escalated quickly in Europe and North America in March 2020. Now, nearly a year after the outbreak, more than 74 million people have been infected with the virus worldwide, and more than one and a half million have died (John Hopkins University, 2020). As the virus spread throughout 
Asia and Europe, a tense scenario was occurring in Latin America as the population waited for the first cases to be reported while learning about the virus's spread, mode of infection, and the need for quarantine.

After almost nine months of strict social isolation, the high incidence of depression and anxiety is understandable. However, these conditions can adversely affect the quality of life. Fear or stress can create functional disturbances in the prefrontal cortex, amygdala, and hippocampus. These disturbances can be expressed as erratic executive functions and appear as memory loss, low retention, or rapid changes in attention and decision-oriented objectives (McEwen \& Morrison, 2013). A similar situation occurred after the SARS pandemic in 2003 when survivors were diagnosed with posttraumatic stress syndrome, depression, anxiety disorders, and, to a lesser extent, obsessive-compulsive disorder, even four years after the outbreak (Lam et al., 2009). Different levels of stress and fear caused by the COVID-19 pandemic can affect the human psyche. A recent study in the Mexican population reported that during the initial phase of the COVID-19 pandemic, the reported number of episodes increased by up to $51 \%$ for anxiety and $86 \%$ for depression (GarciaPriego et al., 2020). Moreover, the widespread outbreak of infectious diseases, such as COVID-19, is associated with psychological distress (Rajkumar, 2020), fear (Ahorsu et al., 2020; Barbosa-Camacho et al., 2020; GarcíaReyna et al., 2020), anxiety (Cuiyan Wang et al., 2020), and even a new condition known as coronaphobia (Lee, 2020; Lee et al., 2020). The COVID-19 pandemic is an unusual situation that has forced governments to develop programs to guarantee social security and economic stability and improvise strategies to respond, adapt, and overcome daily obstacles to allow the population to continue their lives as normally as possible. (Gobierno de Jalisco, 2020a;2020b).

One fundamental challenge in this pandemic is the need to continue providing education in public and private academic institutes. Most schools worldwide were closed in March (Pragholapati, 2020; Redacción, 2020; UNESCO, 2020). The alternative has been to continue teaching classes online using different platforms such as Skype, Google, Zoom, and others (Chick et al., 2020). The use of online education has increased markedly in the past two decades because of its advantages over face-to-face delivery. However, the rapid integration of virtual education in the face of the current crisis has diverted attention from this modality's main challenges (Kebritchi et al., 2017). Changing from classroom-based teaching to online delivery is not a challenge for students in the normal situation; however, being quarantined can be stressful and frustrating, challenging effective learning. Given that the current pandemic scenario is new, we were interested in whether the change to online education affects university students' perceptions of their learning and performance.

\section{Methods}

\section{Aims}

This study aimed to identify undergraduate and graduate students' preference for class modality (classroom or online) and to explore whether the presence of mental health disorders, such as depression or anxiety related to the COVID-19 pandemic, altered their perception of their academic performance.

\section{Study design}


This study was a cross-sectional survey study in which we used the Academic Self-Concept Scale (ASCS) (Woon Chia Liu \& Wang, 2005), the Patient Health Questionnaire-9 (PHQ-9) depression screening scale, and the General Anxiety Disorder-7 (GAD-7) screening scale. The participants were asked about their gender, age, and preference for teaching modality (classroom or online) and whether they perceived any change in their performance or grades during the pandemic. The survey was distributed online through the authors' social media accounts or acquaintances from April to June 2020.

Participants were invited to send the survey to other undergraduate and graduate students to obtain a snowball sampling effect. The inclusion criteria were $>18$ years old and enrollment in any undergraduate or graduate course but attending online. The exclusion criteria were not attending an online course or not being registered in a university undergraduate or graduate course.

\section{Instruments}

To evaluate academic performance, we used the ASCS. This instrument is a 20-question inventory with a Likert scale of four options: "strongly disagree," "disagree," "agree," and "strongly agree," which are used to explore a student's perception of his/her academic performance. The scoring is divided into two subscales: Confidence, which evaluates the student's academic competence through the course, and Effort, which evaluates the student's commitment and interest in the course. To evaluate depression, we used the PHQ-9 Questionnaire, a nine-question inventory used to identify the presence and intensity of a depressive disorder. No risk of depression or minimal risk was defined when a score of 0 to 4 was obtained, mild depression when it was 5 to 9, moderate depression with a score of 10 to 14, moderately severe depression from 15 to 19 and severe depression with a score greater than 20. GAD-7 questionnaire was used to assess anxiety. This seven-item questionnaire assesses the presence and intensity of anxiety disorders. A score of 5-9 represents mild anxiety, 10-14 moderate anxiety, and greater than 15 severe anxiety.

\section{Data analysis}

The data analysis was performed using SPSS Statistics software. The descriptive analyses included proportions, means, and standard deviations. The inferential analysis was performed using the chi-squared test, analysis of variance (ANOVA), and Student's t-test. Additionally, post hoc analysis was performed using Tukey honestly significant difference (HSD) and Bonferroni test. A probability level of $p<0.05$ was considered to be significant.

\section{Results}

A total of 720 students answered the survey; 110 surveys were excluded from the study because they were incomplete, resulting in 610 (84.7\%) completed surveys from 386 female students (63.3\%) and 224 male students $(36.7 \%)$. The mean age was $20.58 \pm 3.27$ years. The rest of the demographic characteristics are presented in Table 1. 


\begin{tabular}{|ll|}
\hline \multicolumn{2}{|l|}{ Table 1. Demographic characteristics } \\
\hline Age $($ mean, SD) & $20.58 \pm 3.27$ \\
\hline Gender $(\mathrm{n}, \%)$ & $386(63.3 \%)$ \\
\hline Female & $224(36.7 \%)$ \\
\hline Male & \\
\hline Semester $(\mathrm{n}, \%)$ & $16(2.6 \%)$ \\
\hline 1 & $227(37.2 \%)$ \\
\hline 2 & $49(8.0 \%)$ \\
\hline 3 & $121(17.4 \%)$ \\
\hline 4 & $20(3.3 \%)$ \\
\hline 5 & $48(7.9 \%)$ \\
\hline 6 & $39(6.4 \%)$ \\
\hline 7 & $60(9.8 \%)$ \\
\hline 8 & $30(4.9 \%)$ \\
\hline 9 & $8(1.3 \%)$ \\
\hline 10 & $1(0.2 \%)$ \\
\hline 11 & $1(0.2 \%)$ \\
\hline 12 & \\
\hline Field of study(n, \%) & $13(2.1 \%)$ \\
\hline Arts and design & $22(3.6 \%)$ \\
\hline Biological Sciences & $69(11.3 \%)$ \\
\hline Humanitarian and political sciences & $50(8.2 \%)$ \\
\hline
\end{tabular}

From the total sample, 436 students $(71.5 \%)$ had not, and 174 students $(28.5 \%)$ had taken an online course before. When asked about their class preferences, 581 students (95.2\%) preferred classroom classes, and 29 students $(4.8 \%)$ preferred online classes.

When asked whether their perception of their academic performance had changed after transitioning to online learning, 493 students (80.8\%) felt that their performance had worsened, 84 students (13.8\%) felt that their 
performance had stayed the same as before, and 33 students (5.4\%) felt that their performance had improved. When asked whether their grades had changed since the transition to online learning, 296 students (48.5\%) responded that their grades had stayed the same as before, 247 students (40.5\%) reported worse grades compared with previous grades in classroom classes, and 67 students (11\%) reported better grades than before.

The average ASCS score was $2.76 \pm 0.35$. The ASCS subscales were used to assess the Confidence and Effort categories. The total sample mean scores were $2.71 \pm 0.37$ for Confidence and $2.82 \pm 0.45$ for Effort. The total mean PHQ-9 score was $11.94 \pm 6.90$, and the mean GAD-7 score was $10.30 \pm 5.66$. The depression and anxiety frequencies are presented in Table 2.

Table 2. Mean ACSC Confidence and Effort scores grouped according to depression and anxiety identified with the GAD-7 and PHQ-9.

\begin{tabular}{lllll}
\hline Depression Groups & $\mathbf{n}(\%)$ & $\begin{array}{l}\text { Confidence Mean } \\
\text { Scores }\end{array}$ & $\begin{array}{l}\text { Effort Mean } \\
\text { Scores }\end{array}$ & $\begin{array}{l}\text { AScS overall } \\
\text { Scores }\end{array}$ \\
\hline Minimal or none & $\begin{array}{l}103 \\
(16.9 \%)\end{array}$ & $2.82 \pm 0.41$ & $2.87 \pm 0.50$ & $2.85 \pm 0.42$ \\
\hline Mild Depression & $\begin{array}{l}132 \\
(21.6 \%)\end{array}$ & $2.81 \pm 0.38$ & $2.87 \pm 0.43$ & $2.84 \pm 0.34$ \\
\hline Moderate Depression & $\begin{array}{l}168 \\
(27.5 \%)\end{array}$ & $2.69 \pm 0.32$ & $2.82 \pm 0.46$ & $2.75 \pm 0.35$ \\
\hline $\begin{array}{l}\text { Moderately severe } \\
\text { Depression }\end{array}$ & $\begin{array}{l}110 \\
(18.0 \%)\end{array}$ & $2.62 \pm 0.34$ & $2.79 \pm 0.40$ & $2.71 \pm 0.30$ \\
\hline Severe Depression & $\begin{array}{l}97 \\
(15.9 \%)\end{array}$ & $2.57 \pm 0.37$ & $2.73 \pm 0.43$ & $2.65 \pm 0.32$ \\
\hline
\end{tabular}

\section{Anxiety Groups}

Minimal or none

130

$2.81 \pm 0.40$

$2.86 \pm 0.46$

$2.84 \pm 0.39$

(21.3\%)

Mild Anxiety

210

(34.4\%)

$2.71 \pm 0.35$

$2.80 \pm 0.45$

$2.75 \pm 0.35$

Moderate Anxiety

146

(23.9\%)

$2.66 \pm 0.32$

$2.81 \pm 0.42$

$2.73 \pm 0.31$

Severe Anxiety

124

$2.64 \pm 0.41$

$2.82 \pm 0.45$

$2.73 \pm 0.36$

$(20.3 \%)$

\section{Co-diagnosis groups}

Both depression and anxiety 447 (73.3\%)

Depression only $60(9.8 \%)$

$2.67 \pm 0.36$

$2.80 \pm 0.44$

$2.74 \pm 0.34$

Anxiety only $33(5.4 \%)$

$2.80 \pm 0.36$

$2.83 \pm 0.38$

$2.81 \pm 0.31$

Neither anxiety nor depression

$2.79 \pm 0.38$

$2.85 \pm 0.45$

$2.82 \pm 0.36$

Notes: Data is presented as mean scores and standard deviation. 
Student's T test for independent samples was employed to contrast PHQ-9 and GAD-7 scores with the students' perception of their performance (better or worse). The groups' mean and t scores are presented in Table 3.

Table 3. Perceived academic performance and grade changes groups comparisons in PHQ-9 and GAD-7 mean scores.

\begin{tabular}{|c|c|c|c|c|}
\hline $\begin{array}{l}\text { Perceived academic performance } \\
\text { change }\end{array}$ & $\begin{array}{l}\text { PHQ-9 mean } \\
\text { scores }\end{array}$ & $\begin{array}{l}t \\
\text { scores }\end{array}$ & $\begin{array}{l}\text { GAD-7 mean } \\
\text { scores }\end{array}$ & $t$ scores \\
\hline Better performance & $11.30 \pm 8.31$ & \multirow[t]{2}{*}{-0.86} & $10.72 \pm 6.35$ & \multirow[t]{2}{*}{0.46} \\
\hline Worse Performance & $12.58 \pm 6.70$ & & $10.68 \pm 5.54$ & \\
\hline \multicolumn{5}{|l|}{ Grade changes } \\
\hline Better grades & $11.65 \pm 6.69$ & \multirow[t]{2}{*}{$-2.54 \star \star$} & $9.95 \pm 5.53$ & \multirow[t]{2}{*}{$-2.55^{\star \star}$} \\
\hline Worse grades & $14.04 \pm 6.77$ & & $11.88 \pm 5.47$ & \\
\hline
\end{tabular}

One-way between-group ANOVA was used to compare the ASCS scores according to the severity of depression. There was a significant effect of the severity of depression on the ASCS scores $(F(4,605)=6.506, p<0.001)$. Post hoc comparisons using the Tukey honestly significant difference (HSD) test indicated that ASCS mean score differed significantly between the mild depression group and the moderately severe and severe depression groups. The mean ASCS scores also differed significantly between the severe and moderately severe depression groups compared with the minimal to no depression group. These differences continued after adjusting for multiple comparisons using the Bonferroni Test. For the mean ASCS scores, the severity of anxiety differed between groups $(F(3,606)=2.631, p<0.05)$. The ASCS score differed between the no anxiety group and the moderate and severe anxiety groups. Different results persisted even after adjusting for multiple comparisons using the Bonferroni test.

One-way between-group ANOVA was used to compare the mean ASCS Confidence and Effort subscale scores according to the severity of depression. There was a significant effect of the severity of depression on the Confidence score $(F(4,609)=10.290, p<0.001)$. The mean Confidence scores differed significantly between the severe depression group and the minimal or no depression and mild depression groups. These differences also persisted after adjusting for multiple comparisons using the Bonferroni test. The mean Effort subscale scores did not differ significantly according to the severity of depression $(F(4,609)=1.924, p>0.05)$.

One-way between-group ANOVA was used to compare the Confidence and Effort scores according to the severity of anxiety. There was a significant effect of anxiety on Confidence scores $(F(3,609)=5.808, p<0.001)$. Post hoc comparisons using the Tukey HDS test indicated that the Confidence score differed significantly between the no to minimal anxiety group and the moderate and severe anxiety groups. These differences 
continued after adjusting for multiple comparisons using the Bonferroni test. The mean Effort subscale scores did not differ significantly according to the severity of anxiety $(F(3,609)=0.606, p>0.05)$.

\section{Discussion}

Currently, the COVID-19 pandemic is a public health emergency of international concern, and governments have had to improvise strategies to keep afloat essential sectors such as education. Because of the conditions caused by the pandemic, UNESCO supports countries in their efforts to reduce the immediate impact of school closures and facilitate the continuity of education for all through distance learning, such as online learning programs (UNESCO, 2020). In the USA, student preference for fully online courses has increased in recent years (Ortagus, 2017), but the student population in Mexico does not seem comfortable with the idea of distance education, and most students still prefer face-to-face academic programs. Additionally, as many students may be struggling psychologically because of the overall situation, it could be challenging for most students to maintain the same enthusiasm for online classes as for the face-to-face classroom environment.

Parapi et al. identified the necessary skills and possible challenges of virtual education for both students and teachers as the lack of interest and enthusiasm because students must be self-motivated, inadequacy in the technological skills needed by teachers and suppliers of materials, the attention span, and distractions outside the classroom, and the shortage of equipment, access, and internet connection (Parapi et al., 2020). Possible content-related issues include the role of instructors in content development and integration of multimedia. Instructors must modify their teaching style, time management, and adaptation of the transition from face-toface to virtual teaching. The absence of programs to prepare for this educational transition can directly impact the education of students. Therefore, students must understand and take full responsibility for their learning needs, goals, and strategies (Kebritchi et al., 2017).

In a survey of 488 students, Al-Azzam et al. reported the factors that positively enhance students' preference for virtual learning: easy access to online tools, class engagement, increased attendance, and lack of anxiety during the pandemic and saving time (Al-Azzam et al., 2020). The high incidence of anxiety and depression may have directly affected the virtual learning experience in our sample.

Social isolation is associated with reduced interpersonal communication and may increase students' feelings of loneliness (Tang et al., 2020). The growing uncertainty about the outbreak's progression (Huang \& Zhao, 2020), together with constant exposure to news about COVID-19 via social media (Ni et al., 2020), may further increase psychological distress.

Whether and how stress can positively or negatively affect students' academic performance is not clear, although there are different theories to explain this. In a study of nursing students that assessed the impact of stress factors and depressive symptoms on academic performance, higher stress rates were associated with better individual semester performance, which suggests a positive impact of stress on academic performance (Ferreira da Fonseca et al., 2019). Nevertheless, academic performance may be more susceptible because depressive symptoms can interfere with intellectual activity, contributing to school failure (Rojas García \& Ruggero, 2013). Our results are consistent with Rojas Garcia and Ruggero because most of our students reported that their academic performance worsened at the beginning of the online classes, and they perceived worse grades than before. These findings suggest that negative emotions and online learning required because 
of the pandemic probably played an essential role in creating psychological distress, which may have interfered with students' ability to manage their educational responsibilities during this time.

The sudden outbreak of COVID-19 has inevitably caused anxiety, depression, and other stress reactions among the general population and limited daily life and social activities for an unknown period (Wang et al., 2020). Public health emergencies can have psychological effects on college students, which may be expressed as anxiety, fear, and worry, among other things (Cao et al., 2020). Our study found that more than $80 \%$ of our student sample were distressed and had mild to severe anxiety and depression after the beginning of the COVID-19 outbreak. This prevalence is higher than that reported by a study in the U.S. 1 month after the declared state of emergency, where at least one-third of young adults reported having clinically elevated levels of depression and anxiety (Liu et al., 2020). Another study in China of younger people aged <35 years reported prevalence rates of anxiety and depression symptoms of $35.1 \%$ and $20.1 \%$, respectively (Huang \& Zhao, 2020). A study of 7,143 students in China reported that $24.9 \%$ experienced some degree of anxiety: $0.9 \%$ experienced severe anxiety, 2.7\% moderate anxiety, and 21.3\% mild anxiety (Cao et al., 2020). Our sample had a higher prevalence of anxiety; most students reported experiencing anxiety, and more than one-fifth of the students met the cutoff scores for each category of mild, moderate, and severe anxiety. This finding indicates that the pandemic has had a negative psychological impact on university students in Mexico. Another study in China also reported a higher prevalence of anxiety in students than in the general population during the outbreak (Chongying Wang \& Zhao, 2020).

Our students' psychological challenges may be higher because of the more extended home quarantine after three months of social isolation. More than $50 \%$ of students developed moderate to severe anxiety or depression, and about three-quarters reported both symptoms. This is of concern because of the possible trend toward a higher incidence of posttraumatic stress disorder (PTSD). According to a Chinese study of 2,485 undergraduate students, after 1-month isolation, the prevalence of PTSD was $2.7 \%$, and depression was $9 \%$. Moreover, students who felt extremely scared during the outbreak, those living in the worst-hit areas, and graduating/final year students were found to have the highest risk of developing PTSD and depression (Tang et al., 2020).

In a study of 1,826 German university students, the sudden change from face-to-face teaching to online delivery resulted in digital inequality. Two groups were found in the sample: students with excellent preconditions for studying in a digital format, such as access to equipment and skills for participating, and problematic preconditions related to other aspects of disadvantage. This latter group was found to have higher scores for tension, overload, worries, and emotional loneliness and to experience more significant stress (Händel et al., 2020).

In our sample, severe scores for anxiety and depression were more prevalent than mild scores. These findings are consistent with that of a study of Spaniard university students in which $34.1 \%$ of participants reported moderate to severe depression, $21.3 \%$ reported moderate to severe anxiety symptoms, and $50.4 \%$ of their symptoms were related to a moderate or severe psychological impact during the outbreak and lockdown (Odriozola-González et al., 2020). Only $11 \%$ of our students referred to themselves as emotionally stable, which is an alarmingly low percentage and shows the importance of providing psychological resources to address social isolation during the pandemic until regular activity resumes. 
The academic performance of our sample was explored using the ASCS. Academic self-concept can be described as the self-perception of one's capabilities or competence in the academic field. This scale has been used to measure secondary education students' performance (Liu \& Wang, 2007; Liu \& Wang, 2005). The authors of the scale suggest that a helpful home environment can elevate the students' academic performance. This situation is particularly relevant to our study because the participants in our sample were attending classes online, and some did not live in a helpful or harmonic environment; for example, many households do not have a specialized area for study. Besides, other family members in the house may contribute to distractions or interruptions during class time.

Our sample reported lower academic self-concept scores than those reported in first-year college students (Haktanir et al., 2018). When exploring the students' mental state in our sample, we found that the higher the PHQ-9 or GAD-7 scores, the lower the ASCS total scores. However, we also found that the participants who met the cutoff scores for moderate anxiety and severe anxiety for the GAD-7 scores presented similar scores in the Effort and Confidence subscales and ASCS overall scores. Although the students with moderate and severe anxiety had lower scores than those with no or minimal anxiety, it seems that the higher levels of anxiety are associated with a similar level of effort. Some students noted that anxiety and stress often inspired them to put in greater effort in their studies.

\section{Conclusion}

The COVID-19 pandemic has directly impacted students' performance and the ability to receive information. Like most countries, Mexico has had to improvise strategies to continue providing education at all levels. These strategies have addressed the operational aspects, but the psychological impact of confinement and other factors related to the pandemic has led to an increase in students' incidence of depression and anxiety. This trend may contribute to barriers that prevent proper learning and affect students' preparation, grades, and performance. Strategies should be created to support students continue their academic program through distance learning as social isolation is used to limit the possible spread of disease. However, this must be delivered in a way that avoids imposing barriers to learning. Such strategies must incorporate an understanding of how stressful and complicated social isolation can be.

\section{Abbreviations}




\begin{tabular}{ll} 
ANOVA & Analysis Of Variance \\
\hline ASCS & Academic Self-Concept Scale \\
\hline COVID-19 & CoronaVirus Disease-19 \\
\hline GAD-7 & General Anxiety Disorder-7 \\
\hline HSD & Honestly Significant Difference \\
\hline PHQ-9 & Patient Health Questionnarie-9 \\
\hline PTSD & Post-Traumatic Stress Disorder \\
\hline SARS & Severe Acute Respiratory Syndrome \\
\hline UNESCO & Educational, Scientific and Cultural organization
\end{tabular}

\section{Declarations}

\section{Ethics approval and consent to participate}

Verbal and written authorization was obtained from each participant. The surveys were anonymous to guarantee the confidentiality of each participant. This study complies with national committees' ethical standards on human experimentation and the Helsinki Declaration of 1975, as revised in Fortaleza, Brazil 2013. The study protocol was submitted to ClinicalTrials.gov and registered with the identifier NCT04420416.

\section{Consent for publication}

Not applicable

\section{Availability of data and materials}

The datasets used and/or analysed during the current study are available from the corresponding author on reasonable request.

\section{Autors'contributions}

FJBC conceived the idea of the study. All authors contributed to the study's conception and design. OMRL, JCIP, and YLAM prepared the study material. KJPB, VASL, CFO, AOCF, RCMA, GACC, GCC and AGO assisted with the student recruitment process and distribution of the surveys. OMRL, JMCC, BGGR and JMCC performed the data and survey management. FJBC, JCIP, and AGO performed data analysis. FJBC, JCIP, JMCC, VASL and BGGR wrote the first draft of the manuscript. All authors critiqued all versions of the manuscript. All authors read and approved the final manuscript.

\section{Disclosure statement}

The authors declared no potential conflict of financial interests.

\section{Funding details}


The authors received no financial support for the research, authorship, and publication of this article.

\section{Acknowledgments}

The authors wish to acknowledge all physicians, nurses, and other health personnel fighting against COVID-19.

\section{References}

Ahorsu, D. K., Lin, C., Imani, V., Saffari, M., Griffiths, M. D., \& Pakpour, A. H. (2020). The Fear of COVID-19 Scale: development and initial validation. International Journal of Mental Health and Addiction, 1-9.

https://doi.org/10.1007/s11469-020-00270-8

Al-Azzam, N., Elsalem, L., \& Gombedza, F. (2020). A cross-sectional study to determine factors affecting dental and medical students' preference for virtual learning during the COVID-19 outbreak. Heliyon, 6(12).

https://doi.org/10.1016/j.heliyon.2020.e05704

Barbosa-Camacho, F. J., García-Reyna, B., Cervantes-Cardona, G. A., Cervantes-Pérez, E., Chavarria-Avila, E., Pintor-Belmontes, K. J., Guzmán-Ramírez, B. G., Hernández-Bernal, A., Carlos Ibarrola-Peña, J., Fuentes-Orozco, C., González-Ojeda, A., \& Cervantes-Guevara, G. (2020). Comparison of Fear of COVID-19 in Medical and Nonmedical Personnel in a Public Hospital in Mexico. https://doi.org/10.21203/rs.3.rs-37662/v1

Cao, W., Fang, Z., Hou, G., Han, M., Xu, X., Dong, J., \& Zheng, J. (2020). The psychological impact of the COVID19 epidemic on college students in China. Psychiatry Research, 287, 112934.

https://doi.org/10.1016/j.psychres.2020.112934

Chick, R. C., Clifton, G. T., Peace, K. M., Propper, B. W., Hale, D. F., Alseidi, A. A., \& Vreeland, T. J. (2020). Using technology to maintain the education of residents during the COVID-19 pandemic. Journal of Surgical Education, 77(4), 729-732. https://doi.org/10.1016/j.jsurg.2020.03.018

Ferreira da Fonseca, J. R., Siqueira Costa Calache, A. L., Rodrigues dos Santos, M., Marques da Silva, R., \& Alvarez Moretto, S. (2019). Association of stress factors and depressive symptoms with the academic performance of nursing students. Revista Da Escola de Enfermagem Da USP, 53.

https://doi.org/10.1590/S1980-220X2018030403530

Garcia-Priego, B. A., Triana-Romero, A., Pinto-Galvez, S. M., Duran-Ramos, C., Salas-Nolasco, O., Reyes, M. M., Medina, A. R. de la, \& Troche, J. M. R. (2020). Anxiety, depression, attitudes, and internet addiction during the initial phase of the 2019 coronavirus disease (COVID-19) epidemic: A cross-sectional study in Mexico. MedRxiv, 2020.05.10.20095844. https://doi.org/10.1101/2020.05.10.20095844

García-Reyna, B., Castillo-García, G. D., Barbosa-Camacho, F. J., Cervantes-Cardona, G. A., Cervantes-Pérez, E., Torres-Mendoza, B. M., Fuentes-Orozco, C., Pintor-Belmontes, K. J., Guzmán-Ramírez, B. G., Hernández-Bernal, A., González-Ojeda, A., \& Cervantes-Guevara, G. (2020). Fear of COVID-19 Scale for hospital staff in regional hospitals in Mexico: a brief report. International Journal of Mental Health and Addiction, 19. https://doi.org/10.1007/s11469-020-00413-x 
Gobierno de Jalisco. (2020a). Criterios para la activación del botón de emergencia. [Criteria for the emergency button activation] https://coronavirus.jalisco.gob.mx/criterios-para-la-activacion-del-boton-de-emergencia/

Gobierno de Jalisco. (2020b). Con el objetivo de salvar vidas, reducir los contagios y evitar el colapso de hospitales, las medidas de aislamiento social y el uso de cubrebocas en la calle serán obligatorios en Jalisco. [In order to save lives, reduce contagion and avoid the collapse of hospitals, social isolation measures and the use of face masks on the street will be mandatory in Jalisco] https://www.jalisco.gob.mx/es/prensa/noticias/103420

Haktanir, A., Watson, J. C., Ermis-Demirtas, H., Karaman, M. A., Freeman, P. D., Kumaran, A., \& Streeter, A. (2018). Resilience, academic self-concept, and college adjustment among first-year students. Journal of College Student Retention: Research, Theory \& Practice. https://doi.org/10.1177/1521025118810666

Händel, M., Stephan, M., Gläser-Zikuda, M., Kopp, B., Bedenlier, S., \& Ziegler, A. (2020). Digital readiness and its effects on higher education students' socio-emotional perceptions in the context of the COVID-19 pandemic. Journal of Research on Technology in Education, 1-13. https://doi.org/10.1080/15391523.2020.1846147

Huang, Y., \& Zhao, N. (2020). Mental health burden for the public affected by the COVID-19 outbreak in China: Who will be the high-risk group? Psychology, Health and Medicine.

https://doi.org/10.1080/13548506.2020.1754438

John Hopkins University. (2020). Coronavirus COVID-19 (2019-nCoV).

https://gisanddata.maps.arcgis.com/apps/opsdashboard/index.html\#/bda7594740fd40299423467b48e9ecf6

Kebritchi, M., Lipschuetz, A., \& Santiague, L. (2017). Issues and challenges for teaching successful online courses in higher education. Journal of Educational Technology Systems, 46(1), 4-29.

https://doi.org/10.1177/0047239516661713

Lam, M. H. B., Wing, Y. K., Yu, M. W. M., Leung, C. M., Ma, R. C. W., Kong, A. P. S., So, W. Y., Fong, S. Y. Y., \& Lam, S. P. (2009). Mental morbidities and chronic fatigue in severe acute respiratory syndrome survivors: Long-term follow-up. Archives of Internal Medicine, 169(22), 2142-2147. https://doi.org/10.1001/archinternmed.2009.384

Lee, S. A. (2020). Replication analysis of the Coronavirus Anxiety Scale. Dusunen Adam: The Journal of Psychiatry and Neurological Sciences, 33(2), 203-205. https://doi.org/10.14744/dajpns.2020.00079

Lee, S. A., Jobe, M. C., Mathis, A. A., \& Gibbons, J. A. (2020). Incremental validity of coronaphobia: Coronavirus anxiety explains depression, generalized anxiety, and death anxiety. Journal of Anxiety Disorders, 74, 102268. https://doi.org/10.1016/j.janxdis.2020.102268

Liu, C. H., Zhang, E., Wong, G. T. F., Hyun, S., \& Hahm, H. (2020). Factors associated with depression, anxiety, and PTSD symptomatology during the COVID-19 pandemic: Clinical implications for U.S. young adult mental health. Psychiatry Research, 290, 113172. https://doi.org/10.1016/j.psychres.2020.113172

Liu, W.C., \& Wang, C. K. J. (2007). The effects of perceived home environment and classroom climate on male and female students' academic self-concept. Journal of Education, 5(1), 52-71. 
Liu, Woon Chia, \& Wang, C. K. J. (2005a). Academic self-concept: A cross-sectional study of grade and gender differences in a Singapore secondary school. Asia Pacific Education Review, 6(1), 20-27.

https://doi.org/10.1007/BF03024964

McEwen, B. S., \& Morrison, J. H. (2013). The brain on stress: Vulnerability and plasticity of the prefrontal cortex over the life course. Neuron, 79(1), 16-29. https://doi.org/10.1016/j.neuron.2013.06.028

Parapi, J. M. O., Maesaroh, L. I., Basuki, B. \& Masykuri, E. S. (2020). Virtual education: a brief overview of its role in the current educational system. In Scripta: English Department Journal7(1).

http://jurnal.umpwr.ac.id/index.php/scripta/article/view/632

Ni, M. Y., Yang, L., Leung, C. M. C., Li, N., Yao, X. I., Wang, Y., Leung, G. M., Cowling, B. J., \& Liao, Q. (2020). Mental health, risk factors, and social media use during the COVID-19 epidemic and cordon sanitaire among the community and health professionals in Wuhan, China: Cross-sectional survey. JMIR Mental Health, 7(5), e19009. https://doi.org/10.2196/19009

Odriozola-González, P., Planchuelo-Gómez, Á., Irurtia, M. J., \& de Luis-García, R. (2020). Psychological effects of the COVID-19 outbreak and lockdown among students and workers of a Spanish university. Psychiatry Research, 290, 113108. https://doi.org/10.1016/j.psychres.2020.113108

Ortagus, J. C. (2017). From the periphery to prominence: An examination of the changing profile of online students in American higher education. Internet and Higher Education, 32, 47-57.

https://doi.org/10.1016/j.iheduc.2016.09.002

Pragholapati, A. (2020). COVID-19 impact on students. EdArXiv Preprints.

https://doi.org/10.35542/osf.io/895ed

Rajkumar, R. P. (2020). COVID-19 and mental health: A review of the existing literature. Asian Journal of Psychiatry, 52. https://doi.org/10.1016/j.ajp.2020.102066

Redacción. (2020, March 16). Publica DOF acuerdo de suspensión de clases a nivel nacional por Covid-19 [DOF publishes agreement to suspend classes at the national level due to Covid-19]. La Jornada.

https://www.jornada.com.mx/ultimas/sociedad/2020/03/16/publica-dof-acuerdo-de-suspension-de-clases-anivel-nacional-por-covid-19-5707.html

Rojas García, A., \& Ruggero, C. (2013). Depresión, ansiedad y rendimiento académico en estudiantes universitarios. [Depression, anxiety and academic performance in college students]. Revista Intercontinental de Psicología y Educación, 15(1), 47-60. https://www.redalyc.org/comocitar.oa?id=80225697004

Tang, W., Hu, T., Hu, B., Jin, C., Wang, G., Xie, C., Chen, S., \& Xu, J. (2020). Prevalence and correlates of PTSD and depressive symptoms one month after the outbreak of the COVID-19 epidemic in a sample of home-quarantined Chinese university students. Journal of Affective Disorders, 274, 1-7. https://doi.org/10.1016/j.jad.2020.05.009

UNESCO. (2020). School closures caused by Coronavirus (Covid-19). UNESCO.

https://en.unesco.org/covid19/educationresponse

Page $15 / 16$ 
Wang, Chongying, \& Zhao, H. (2020). The impact of COVID-19 on anxiety in Chinese university students.

Frontiers in Psychology, 11, 1168. https://doi.org/10.3389/fpsyg.2020.01168

Wang, Cuiyan, Pan, R., Wan, X., Tan, Y., Xu, L., Mclntyre, R. S., Choo, F. N., Tran, B., Ho, R., Sharma, V. K., \& Ho, C. (2020). A longitudinal study on the mental health of general population during the COVID-19 epidemic in China. Brain, Behavior, and Immunity. 87(1) 40-48. https://doi.org/10.1016/j.bbi.2020.04.028

Wang, Y., Di, Y., Ye, J., \& Wei, W. (2020). Study on the public psychological states and its related factors during the outbreak of coronavirus disease 2019 (COVID-19) in some regions of China. Psychology, Health \& Medicine, 13-22. https://doi.org/10.1080/13548506.2020.1746817 